\title{
ANALISIS SISTEM DRAINASE DI KAWASAN PERMUKIMAN PADA RUAS JALAN GETAH TUNGGAL KELURAHAN CEMPAKA KOTA BANJARBARU
}

\author{
Fathurrahman ${ }^{1)}$, Akhmad Gazali ${ }^{2)}$ \\ Universitas Islam Kalimantan MAB Banjarmasin \\ Email: ${ }^{1)}$ fathurrahman4715@gmail.com
}

\begin{abstract}
ABSTRAK
Banjir yang terjadi di kota Banjarbaru khususnya yang terjadi di kawasan pemukiman menimbulkan permasalahan bagi masyarakat serta tantangan buat pemerintah untuk mengevaluasi saluran drainase di pemukiman tersebut. Saluran-saluran tempat pengaliran air hujan yang sudah ada perlu dilakukan peninjauan ulang dan pengembangan agar bisa menampung debit air yang mengalir di kawasan tersebut. Salah satu pemukiman yang pernah terjadi banjir di kota Banjarbaru adalah pemukiman penduduk di Kecamatan Cempaka, Kelurahan Cempaka, tepatnya di Jalan Getah Tunggal. Data yang diperlukan dalam penelitian ini adalah data curah hujan, data tata guna lahan, data topografi dan data eksisting kondisi saluran di lokasi studi. Data curah hujan dianalisis dengan metode Log Pearson III, Gumbel dan Iwai Kadoya, kemudian diuji dengan Chi Kuadrat untuk memilih distribusi statistik yang diterima. Data curah hujan tersebut dianalisa ke dalam intensitas hujan jam-jaman menggunakan metode mononobe. Intensitas hujan dianalisa menggunakan metode rasional untuk mendapatkan debit rencana (Qrencana). Selanjutnya (Qrencana) tersebut dibandingkan dengan (Qsaluran), dan (Qeksisting). Berdasarkan hasil perhitungan didapatkan (Qrencana) sebesar 0,76 m³/detik, (Qsaluran) sebesar $0,78 \mathrm{~m}^{3} /$ detik, (Qeksisting) sebesar $0,0645 \mathrm{~m}^{3} /$ detik, diperoleh hasil perbandingan yaitu (Qsaluran) > (Qrencana), (Qeksisting) < (Qrencana). Sehingga dapat disimpulkan bahwa penyebab terjadinya banjir dan genangan air adalah endapan (sedimentasi) setinggi $70 \mathrm{~cm}$ yang mengurangi kapasitas tampungan dimensi awal saluran.
\end{abstract}

Kata Kunci: Evaluasi kapasitas saluran, drainase, banjir, sedimentasi

\begin{abstract}
Floods that occurred in the city of Banjarbaru especially those that occurred in residential areas caused problems for the community as well as challenges for the government to evaluate the drainage channel in the settlement. The existing rainwater drainage channels need to be reviewed and developed so that they can accommodate the water flowing in the area. One of the settlements that had occurred in the city of Banjarbaru was a residential area in Cempaka Subdistrict, Cempaka Village, precisely on Jalan Getah Tunggal. The data needed in this study are rainfall data, land use data, topographic data and existing data on channel conditions at the study site. Rainfall data were analyzed by Log Pearson III, Gumbel and Iwai Kadoya methods, then tested by Chi Square to choose the distribution of statistics received. The rainfall data was analyzed into the intensity of hourly rain using the mononobe method. Rain intensity is analyzed using a rational method to get a plan debit (Qchannel). Furthermore (the plan) is compared with (Qchannel), and (Qexisting). Based on the calculation results obtained (Qplanning) of $0.76 \mathrm{~m}^{3} / \mathrm{sec}$, (Qchannel) of $0.78 \mathrm{~m}^{3} / \mathrm{sec}$, (Qexisting) of 0.0645 $\mathrm{m}^{3} / \mathrm{sec}$, the comparison results are obtained (Qchannel)>(Qplanning), (Qexisting) <(Qplanning). So that it can be concluded that the causes of flooding and inundation are sediments as high as $70 \mathrm{~cm}$ which reduce the storage capacity of the initial dimensions of the channel.
\end{abstract}

Keywords: Channel capacity evaluation, drainage, flood, sedimentation 


\section{PENDAHULUAN}

\section{Latar Belakang}

Sistem drainase merupakan salah satu bagian yang penting dalam perencanaan pembangunan suatu kawasan pemukiman. Sistem drainase yang baik harus dapat menampung pembuangan air semaksimal mungkin, sehingga apabila debit air lebih dari yang diperkirakan, sistem drainase tersebut masih dapat menampung dan mengalirkannya sehingga tidak terjadi genangan air pada saat hujan turun dan banjir pada saat air sungai pasang di kawasan pemukiman tersebut. Selain itu, drainase juga berfungsi untuk mengurangi erosi tanah dan penyaluran dengan meningkatkan infiltrasi air ke dalam tanah.

Banjir yang terjadi di kota Banjarbaru khususnya yang terjadi di kawasan pemukiman menimbulkan permasalahan bagi masyarakat serta tantangan buat pemerintah untuk mengevaluasi saluran drainase di pemukiman tersebut. Saluransaluran tempat pengaliran air hujan yang sudah ada perlu dilakukan peninjauan ulang dan pengembangan agar bisa menampung debit air yang mengalir di kawasan tersebut. Salah satu pemukiman yang pernah terjadi banjir di kota Banjarbaru adalah pemukiman penduduk di Kecamatan Cempaka, Kelurahan Cempaka, tepatnya di Jalan Getah Tunggal. Saluran drainase perkotaan merupakan saluran terbuka.

\section{Rumusan Masalah}

Berdasarkan latar belakang, berikut ini dikemukakan rumusan masalah sebagai berikut:

1. Bagaimana menganalisis debit banjir rencana pada saluran drainase di kawasan pemukiman Jalan Getah Tunggal Kota Banjarbaru dalam periode 10 tahun?

2. Bagaimana menganalisis debit aliran saluran drainase pada penampang awal rencana dan pada penampang saat ini (eksisting) di kawasan pemukiman Jalan Getah Tunggal Kota Banjarbaru?

3. Bagaimana menganalisis dan mengevaluasi faktor penyebab terjadinya banjir dan genangan air di kawasan pemukiman Jalan Getah Tunggal Kota Banjarbaru?

\section{Tujuan Penelitian}

Tujuan penelitian ini adalah sebagai berikut:
1. Menganalisis debit banjir rencana pada saluran drainase di kawasan pemukiman Jalan Getah Tunggal Kota Banjarbaru dalam periode 10 tahun.

2. Menganalisis debit aliran saluran drainase pada penampang awal rencana dan pada penampang saat ini (eksisting) di kawasan pemukiman Jalan Getah Tunggal Kota Banjarbaru.

3. Menganalisis dan mengevaluasi faktor penyebab terjadinya banjir dan genangan air di kawasan pemukiman Jalan Getah Tunggal Kota Banjarbaru.

\section{LANDASAN TEORI}

Debit teoritis/ debit rencana (Qrencana) adalah volume air yang secara teori direncanakan mengalir melewati suatu penampang melintang saluran atau jalur air persatuan waktu berdasarkan hasil analisa hidrologi dan hidrolika. Untuk mendapatkan debit rencana sama dengan debit aliran air $(\mathrm{Q})$ dapat dihitung dengan menggunakan rumus sebagai berikut (SNI 03-3424-1994):

$$
Q=\frac{1}{3,6} \times C \times I \times A
$$

dimana:

$Q=$ debit limpasan $\left(\mathrm{m}^{3} / \mathrm{det}\right)$

$C=$ koefisien pengaliran

$I=$ intensitas curah hujan ( $\mathrm{mm} / \mathrm{jam})$

$A=$ luas daerah pengaliran $\left(\mathrm{km}^{2}\right)$

Perhitungan dimensi saluran didasarkan pada debit harus ditampung oleh saluran (Qsaluran dalam $\mathrm{m}^{3} / \mathrm{det}$ ) lebih besar atau sama dengan debit rencana yang diakibatkan oleh hujan rencana (Qrencana dalam $\mathrm{m}^{3} / \mathrm{det}$ ). Kondisi tersebut dapat dirumuskan dengan persamaan:

Qsaluran $\geq$ Qrencana

Debit yang mampu ditampung oleh saluran (Qsaluran) dapat diperoleh dengan rumus seperti di bawah ini:

$Q s=A s . V$

dimana:

As = luas penampang saluran $\left(\mathrm{m}^{2}\right)$

$V=$ Kecepatan rata-rata aliran di dalam saluran $(\mathrm{m} / \mathrm{det})$ 
Analisis Sistem Drainase di Kawasan..., Fathurrahman ${ }^{(1)}$, Akhmad Gazali (2)

\section{METODE PENELITIAN}

Dalam penyusunan penelitian ini metode penulisan yang digunakan berupa tahapan-tahapan dimulai dari tahapan studi literatur, survey lapangan, tahap pengumpulan data, tahap analisis dan tahap mengambil kesimpulan.

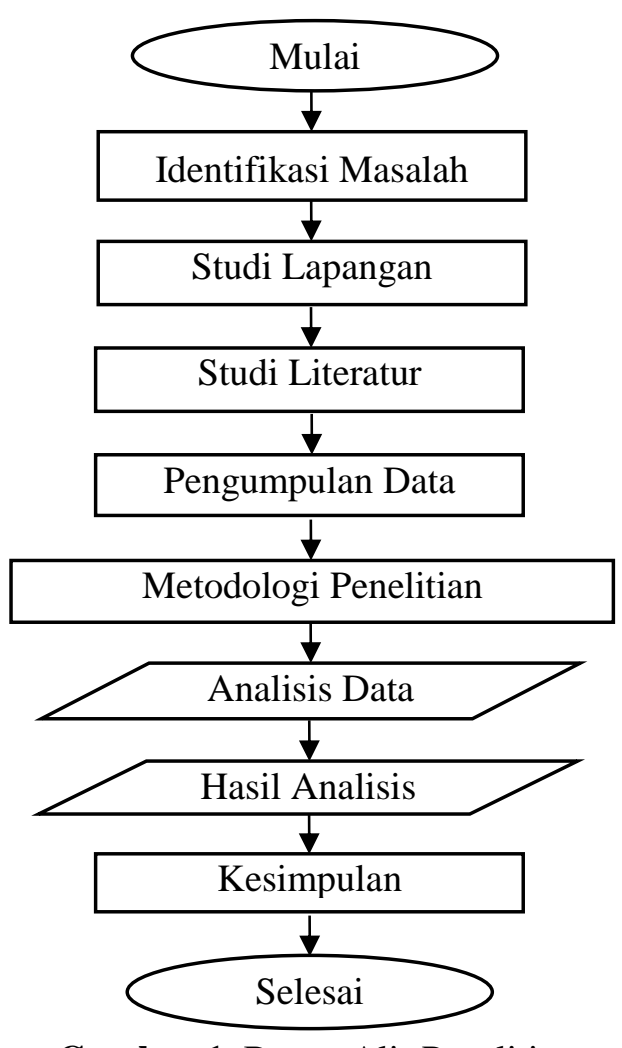

Gambar 1. Bagan Alir Penelitian

\section{HASIL DAN PEMBAHASAN}

\section{Analisis Hidrologi}

Tabel 1. Data Curah Hujan Harian Maksimum

\begin{tabular}{|c|c|c|c|c|}
\hline No & Tahun & $\begin{array}{c}\text { Curah Hujan Maksimum }\left(\mathbf{R}_{\mathbf{i}}\right) \\
(\mathbf{m m})\end{array}$ & $\left(\mathbf{R}_{\mathbf{i}}-\overline{\mathbf{R}}\right)$ & $\left(\mathbf{R}_{\mathbf{i}}-\overline{\boldsymbol{R}}\right)^{\mathbf{2}}$ \\
\hline 1 & 2007 & 28,28 & $-0,07$ & 0,0054 \\
\hline 2 & 2008 & 18,89 & $-9,46$ & 89,5547 \\
\hline 3 & 2009 & 22,60 & $-5,75$ & 33,1008 \\
\hline 4 & 2010 & 24,22 & $-4,13$ & 17,0844 \\
\hline 5 & 2011 & 25,67 & $-2,68$ & 7,2003 \\
\hline 6 & 2012 & 37,11 & 8,76 & 76,6792 \\
\hline 7 & 2013 & 32,77 & 4,42 & 19,5069 \\
\hline 8 & 2014 & 23,81 & $-4,54$ & 20,6419 \\
\hline 9 & 2015 & 33,29 & 4,94 & 24,3707 \\
\hline 10 & 2016 & 28,17 & $-0,18$ & 0,0336 \\
\hline 11 & 2017 & 34,65 & 6,30 & 39,6480 \\
\hline 12 & 2018 & 30,78 & 2,43 & 5,8887 \\
\hline \multicolumn{2}{|c|}{$\sum \mathbf{R}_{\mathbf{i}}$} & 340,24 & \multirow{2}{*}{$\sum\left(\mathbf{R}_{\mathbf{i}}-\overline{\boldsymbol{R}}\right)^{\mathbf{2}}$} & 333,7147 \\
\cline { 1 - 2 } Rerata $(\overline{\boldsymbol{R}})$ & 28,35 & &
\end{tabular}

Sumber: Stasiun Meteorologi Syamsudin Noor Kota Banjarbaru 
Analisis Sistem Drainase di Kawasan..., Fathurrahman ${ }^{(1)}$, Akhmad Gazali ${ }^{(2)}$

Tabel 2. Perhitungan HHM dengan Metode Gumbel

\begin{tabular}{|c|c|}
\hline T (tahun) & HHM dengan Rentang Keyakinan 90\% (mm/jam) \\
\hline 2 & $27,586 \pm 2,407$ \\
\hline 5 & $33,935 \pm 5,089$ \\
\hline 10 & $38,137 \pm 7,315$ \\
\hline 25 & $43,449 \pm 10,233$ \\
\hline 50 & $47,390 \pm 12,427$ \\
\hline 100 & $51,300 \pm 14,618$ \\
\hline
\end{tabular}

Sumber: hasil perhitungan

Tabel 3. Perhitungan HHM dengan Menggunakan Metode Log Person III

\begin{tabular}{|c|c|c|c|c|c|c|c|}
\hline $\mathbf{P U H}$ & $\mathbf{K x} \mathbf{- 0 , 3}$ & $\mathbf{K x} \mathbf{- 0 , 3 9 6 9}$ & $\mathbf{K x}-\mathbf{0 , 4}$ & $\mathbf{S}_{\mathbf{x}}$ & $\mathbf{X}$ & $\mathbf{X}_{\mathbf{T}}$ & $\mathbf{H H M}_{(\mathbf{m m} / \mathbf{2 4 j a m})}$ \\
\hline 2 & 0,050 & 0,065 & 0,066 & 0,0872 & 1,445 & 1,450 & 28,215 \\
\hline 5 & 0,853 & 0,855 & 0,855 & 0,0872 & 1,445 & 1,519 & 33,064 \\
\hline 10 & 1,245 & 1,231 & 1,231 & 0,0872 & 1,445 & 1,552 & 35,661 \\
\hline 25 & 1,643 & 1,607 & 1,606 & 0,0872 & 1,445 & 1,585 & 38,457 \\
\hline 50 & 1,890 & 1,844 & 1,843 & 0,0872 & 1,445 & 1,606 & 40,334 \\
\hline 100 & 2,104 & 2,031 & 2,029 & 0,0872 & 1,445 & 1,622 & 41,877 \\
\hline
\end{tabular}

Sumber: hasil perhitungan

Tabel 4. Perhitungan HHM dengan Metode Iwai Kadoya

\begin{tabular}{|c|c|c|c|c|c|}
\hline \multirow{3}{*}{ PUH } & \multirow{2}{*}{ Tabel X } & $\mathbf{C} *(\mathbf{1} / \mathbf{c})$ & $\mathbf{L o g}(\mathbf{X + b})$ & $\mathbf{X + b}$ & HHM (mm/24jam) \\
\cline { 2 - 6 } & & $\mathbf{1 / c} *(\mathbf{1})$ & $\mathbf{X o +}+\mathbf{( 2 )}$ & $\mathbf{A n t i l o g}(\mathbf{3})$ & $\mathbf{( 4 ) - b}$ \\
\cline { 2 - 6 } & $\mathbf{1}$ & $\mathbf{2}$ & $\mathbf{3}$ & $\mathbf{4}$ & $\mathbf{5}$ \\
\hline 2 & 0,0000 & 0,0000 & 2,354 & 225,973 & 28,292 \\
\hline 5 & 0,5951 & 0,0089 & 2,363 & 230,660 & 32,978 \\
\hline 10 & 0,9062 & 0,0136 & 2,368 & 233,148 & 35,467 \\
\hline 25 & 1,2379 & 0,0185 & 2,373 & 235,831 & 38,150 \\
\hline 50 & 1,4522 & 0,0218 & 2,376 & 237,581 & 39,900 \\
\hline 100 & 1,6450 & 0,0246 & 2,379 & 239,166 & 41,485 \\
\hline
\end{tabular}

Sumber: hasil perhitungan

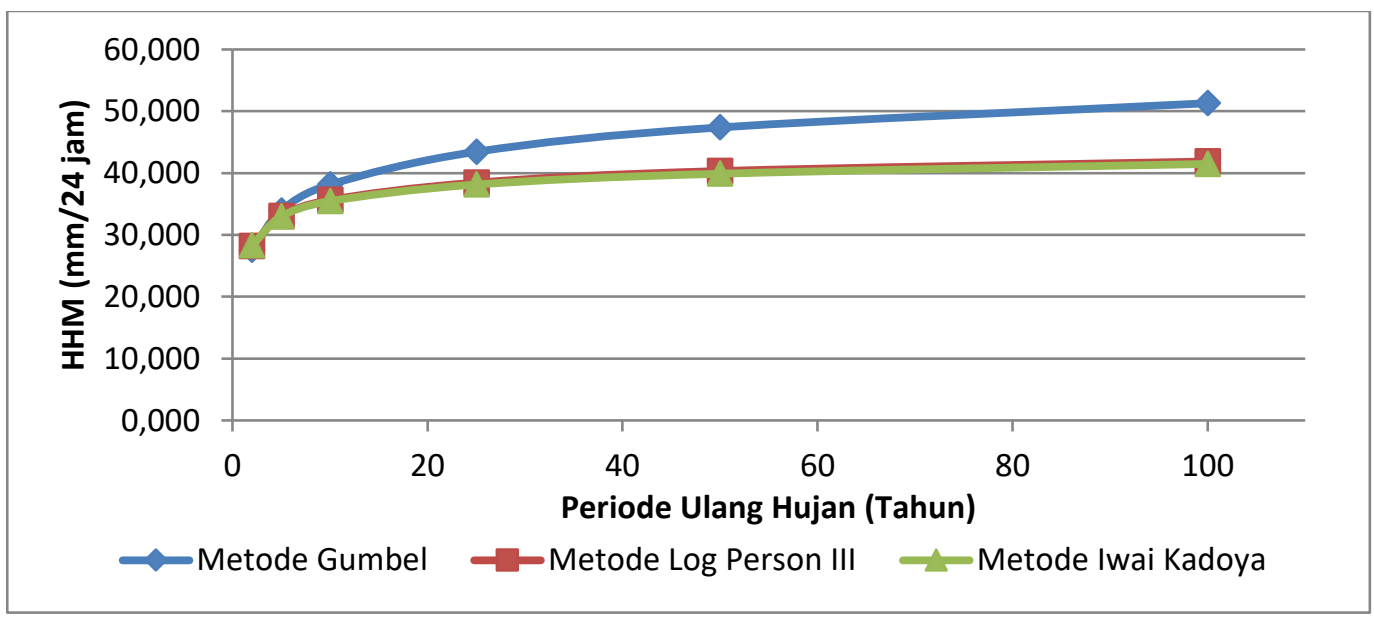

Gambar 2. Perbandingan Nilai Hujan Harian Maksimum 
Analisis Sistem Drainase di Kawasan..., Fathurrahman ${ }^{(1)}$, Akhmad Gazali ${ }^{(2)}$

Tabel 5. Perbandingan Syarat Distribusi dan Hasil Perhitungan

\begin{tabular}{|c|l|l|l|}
\hline No. & \multicolumn{1}{|c|}{ Jenis Distribusi } & \multicolumn{1}{c|}{ Syarat } & Hasil Perhitungan \\
\hline \multirow{2}{*}{1} & \multirow{2}{*}{ Gumbel } & $\mathrm{Cs} \leq 1,1396$ & $0,0521<1,1396$ \\
\cline { 3 - 4 } & & $\mathrm{Ck} \leq 5,4002$ & $2,8994<5,4002$ \\
\hline \multirow{2}{*}{2} & \multirow{2}{*}{ Log Normal } & $\mathrm{Cs}=3 \mathrm{Cv}+\mathrm{Cv}^{2}$ & \\
\cline { 3 - 4 } & & $\mathrm{Cs}=0,6205$ & $0,0521<0,6205$ \\
\hline 3 & Log - Person tipe III & $\mathrm{Cs} \approx 0$ & $0,0521>0$ \\
\hline 4 & Normal & $\mathrm{Cs}=0$ & $0,0521 \neq 0$ \\
\hline
\end{tabular}

Sumber: hasil perhitungan

Tabel 6. Perhitungan Uji Chi-Kuadrat

\begin{tabular}{|c|c|c|c|c|c|}
\hline No. & Nilai Batasan & $\mathbf{O}_{\mathbf{f}}$ & $\mathbf{E}_{\mathbf{f}}$ & $\left(\mathbf{O}_{\mathbf{f}}-\mathbf{E}_{\mathbf{f}}\right)^{\mathbf{2}}$ & $\left(\mathbf{O}_{\mathbf{f}}-\mathbf{E}_{\mathbf{f}}\right)^{\mathbf{2}} / \mathbf{E}_{\mathbf{f}}$ \\
\hline 1 & $15,853 \leq \mathrm{X} \geq 21,926$ & 1 & 3 & 4 & 1,333 \\
\hline 2 & $21,926 \leq \mathrm{X} \geq 27,999$ & 4 & 3 & 1 & 0,333 \\
\hline 3 & $27,999 \leq \mathrm{X} \geq 34,072$ & 5 & 3 & 4 & 1,333 \\
\hline 4 & $34,072 \leq \mathrm{X} \geq 40,145$ & 2 & 3 & 1 & 0,333 \\
\hline & \multicolumn{5}{|c}{ Jumlah } \\
\hline
\end{tabular}

Sumber: hasil perhitungan

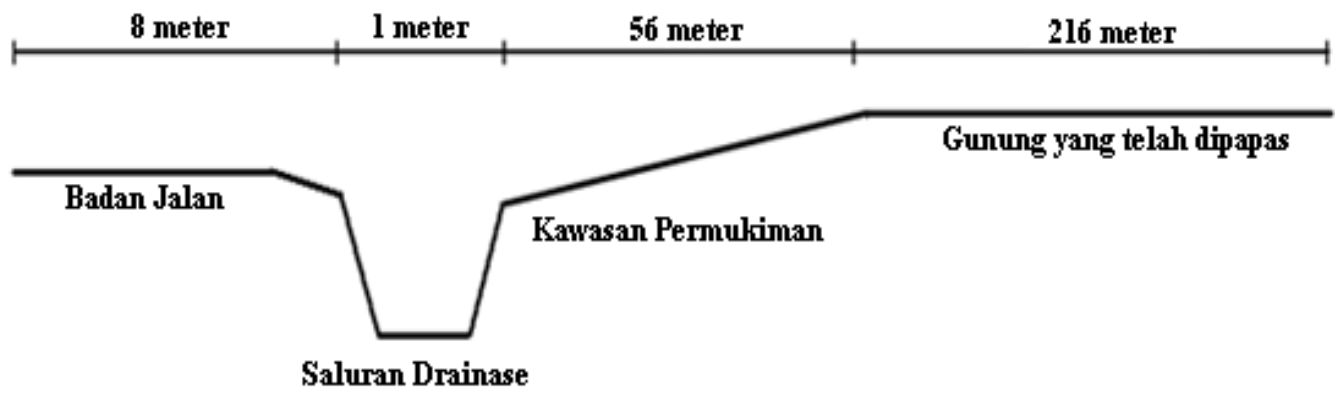

Gambar 3. Potongan Melintang Kondisi Eksisting Lokasi Penelitian

Berdasarkan perbandingan hasil perhitungan dan syarat pada Tabel 5, maka dapat dipilih jenis distribusi yang memenuhi syarat, yaitu Distribusi Gumbel. Dari hasil perhitungan pada Tabel 6 didapat nilai X2 sebesar 3,333 yang kurang dari nilai X2 pada tabel uji Chi-Kuadrat yang besarnya adalah 5,991. Maka dari pengujian kecocokan penyebaran Distribusi Gumbel dapat diterima.

\section{Analisis Hidrolika}

\section{Debit Rencana (Qrencana)}

Berdasarkan Tabel 2 diperoleh nilai hujan maksimum (R) pada periode 10 tahun adalah sebesar $38,137 \mathrm{~mm}$, sehingga dapat dihitung nilai intensitas hujan sebagai berikut.

$I=\frac{R}{24} \times\left[\frac{24}{t_{c}}\right]^{2 / 3}$

$$
I=\frac{38,137}{24} \times\left[\frac{24}{9,02 / 60}\right]^{2 / 3}
$$

$I=46,764 \mathrm{~mm} / \mathrm{jam}$

$Q_{\text {rencana }}=\frac{1}{3,6} \times 0,842 \times 46,764 \times 0,0698=$

$0,7634 \mathrm{~m}^{3} /$ detik

2. Debit Saluran Rencana (Qsaluran)

Analisa ini dilakukan sebagai kontrol terhadap perhitungan debit banjir rencana.

Data yang ada:

$\mathrm{L}=320 \mathrm{~m}$

$\mathrm{I}=0,0000995$

$\mathrm{B}=0,5 \mathrm{~m}$ (lebar saluran) 
$\mathrm{H}=1,0 \mathrm{~m}$ (tinggi saluran)

$\mathrm{m}=2$ (kemiringan dinding saluran)

$\mathrm{Q}_{\mathrm{awal}}=\mathrm{V} \times \mathrm{A}_{\mathrm{p}}=0,315 \times 2,5=0,7875 \mathrm{~m}^{3} / \mathrm{detik}$

\section{Debit Saluran Eksisting (Qeksisting)}

Analisa ini dilakukan sebagai kontrol terhadap perhitungan debit banjir rencana.
Data yang ada:

$\mathrm{L}=320 \mathrm{~m}$

$\mathrm{I}=0,0000995$

$\mathrm{B}=0,7 \mathrm{~m}$ (lebar saluran)

$\mathrm{H}=0,3 \mathrm{~m}$ (tinggi saluran)

$\mathrm{m}=2$ (kemiringan dinding saluran)

Tabel 7. Perbandingan Debit Awal, Debit EkSsisting dan Debit Rencana

\begin{tabular}{|c|c|c|}
\hline $\begin{array}{c}\text { Debit Penampang } \\
\text { Awal }\end{array}$ & $\begin{array}{c}\text { Debit Banjir } \\
\text { Rencana }\end{array}$ & Keterangan \\
\hline 0,7875 & 0,7634 & Tidak Meluap \\
\hline \multicolumn{3}{|c|}{ Keterangan } \\
\hline $\begin{array}{c}\text { Debit Penampang } \\
\text { Eksisting }\end{array}$ & $\begin{array}{c}\text { Debit Banjir } \\
\text { Rencana }\end{array}$ & Meluap \\
\hline 0,0645 & 0,7634 &
\end{tabular}

Berdasarkan hasil perbandingan debit penampang awal terhadap debit banjir rencana, didapat bahwa debit penampang awal $\left(\mathrm{Q}_{\text {awal }}\right)$ lebih besar dari debit banjir rencana $\left(\mathrm{Q}_{\text {rencana }}\right)$. Jadi dapat disimpulkan bahwa penampang drainase awal sebenarnya mampu menampung debit banjir rencana karena kapasitasnya masih mencukupi. Sedangkan berdasarkan hasil perbandingan debit penampang eksisting terhadap debit banjir rencana, didapat bahwa debit penampang eksisting ( $Q_{\text {eksisting }}$ ) lebih kecil dari debit banjir rencana $\left(\mathrm{Q}_{\text {rencana }}\right)$. Jadi dapat disimpulkan bahwa penampang drainase eksisting tidak mampu menampung debit banjir rencana karena kapasitasnya tidak mencukupi. Hal ini yang menyebabkan terjadinya banjir dan genangan air melebihi saluran drainase.

\section{PENUTUP}

\section{Kesimpulan}

1. Berdasarkan hasil perhitungan analisis debit banjir rencana pada saluran drainase di kawasan pemukiman Jalan Getah Tunggal Kota Banjarbaru diperoleh nilai besaran debit banjir dalam periode 10 tahun sebesar 0,7634 $\mathrm{m}^{3} /$ detik.

2. Berdasarkan hasil perhitungan analisis debit aliran saluran drainase pada penampang awal rencana saluran drainase diperoleh nilai besaran debitnya sebesar $0,7875 \mathrm{~m}^{3} /$ detik dan hasil perhitungan analisis debit aliran saluran drainase pada penampang saat ini (eksisting) saluran drainase diperoleh nilai besaran debitnya sebesar $0,0645 \mathrm{~m}^{3} /$ detik.

3. Berdasarkan hasil analisis perbandingan debit aliran saluran drainase pada penampang awal terhadap banjir debit rencana, didapat bahwa debit aliran pada penampang awal $\left(\mathrm{Q}_{\text {awal }}\right)$ lebih besar dari debit banjir rencana $\left(\mathrm{Q}_{\text {rencana }}\right)$. Jadi dapat disimpulkan bahwa penampang drainase awal sebenarnya mampu menampung debit banjir rencana karena kapasitas volume saluran drainase masih mencukupi. Sedangkan berdasarkan hasil analisis perbandingan debit aliran saluran drainase pada penampang eksisting terhadap debit banjir rencana, didapat bahwa debit penampang eksisting (Qeksisting) lebih kecil dari debit banjir rencana ( $\left.\mathrm{Q}_{\text {rencana }}\right)$. Jadi dapat disimpulkan bahwa penampang drainase eksisting tidak mampu menampung debit banjir rencana karena kapasitas volume saluran drainasenya tidak mencukupi. Berdasarkan hasil evaluasi pada kondisi eksisting ditemukan adanya endapan (sedimentasi) yang berada di saluran drainase dengan ketinggian mencapai $70 \mathrm{~cm}$ dari dasar saluran. Kondisi inilah yang menjadi faktor penyebab terjadinya banjir dan genangan air sampai ke badan jalan di kawasan pemukiman Jalan Getah Tunggal Kota Banjarbaru. 


\section{Saran}

1. Berdasarkan hasil kesimpulan di atas, dapat diketahui bahwa penyebab terjadinya banjir dan genangan air adalah endapan (sedimentasi) setinggi $70 \mathrm{~cm}$. Kondisi ini tidak dapat dibiarkan terus berlanjut, diharapkan adanya tindakan oleh pemerintah dan pihak terkait khususnya Dinas Pekerjaan Umum Bidang Sungai dan Drainase untuk melakukan normalisasi (pengerukan) pada saluran drainase tersebut sehingga endapan tersebut dapat dibuang dan tidak meghalangi aliran air yang masuk ke saluran drainase.

2. Melihat dari perbedaan yang sangat kecil antara debit banjir rencana dengan debit penampang awal, sebaiknya dilakukan perencanaan kembali mengenai pembuatan saluran drainase yang lebih besar, sehingga menghasilkan kapasitas debit tampung yang lebih besar pula.

3. Untuk penelitian selanjutnya diharapkan mampu memberikan masukan mengenai perencanaan dimensi saluran drainase yang ideal untuk lokasi penelitian ini.

\section{DAFTAR PUSTAKA}

Benno, Rahardyan. (2009). Identifikasi Permasalahan Sampah Saluran Drainase di Kecamatan Coblong. Bandung. Bandung: Institut Teknologi Bandung

Chow, Ven Te. (1997). Hidrolika Saluran Terbuka, Jakarta: Erlangga

Direktorat Jenderal Bina Marga DPU. Petunjuk Desain Drainase Permukaan Jalan. No. 008/T/BNKT/1990. Jakarta.

Haryono. (1999). Drainase Perkotaan. Departemen Pekerjaan Umum: Jakarta.

Kusuma, Ajeng, et al. (2014). Evaluasi Sistem Saluran Drainase Di Ruas Jalan Solo Sragen

Kabupaten Karanganyar. E-jurnal MATRIKS TEKNIK SIPIL Vol. 2 No. 1 Hal. 170.

Soewarno. (1995). Hidrologi Aplikasi Metode Statistik untuk Analisa Data Jilid I, Bandung: Nova.

Soewarno. (1995). Hidrologi Aplikasi Metode Statistik untuk Analisa Data Jilid II. Bandung: Nova

Suripin, M. (2004). Sistem Drainase Perkotaan yang Berkelanjutan. Penerbit: ANDI. Yogyakarta
Triatmodjo, Bambang. (2003). Hidraulika II. Beta Offset. Yogyakarta

Triatmodjo, Bambang. (2010). Hidrologi Terapan. Beta Offset. Yogyakarta 